\title{
Пути Формирования Рынка Программного Обеспечения В Экономике Знаний
}

\author{
Аловсат Алиев ${ }^{1}$, Вюсала Аббасова ${ }^{2}$ \\ ${ }^{1,2}$ Институт Информационных Технологий НАНА, Баку, Азербайджан \\ lalovsat_qaraca@mail.ru, ${ }^{2}$ vusaleabbaszade@gmail.com
}

\begin{abstract}
Аннотация - В условиях глобализации обеспечение экономического роста требует развития науки, инновации, техники, ИКТ, которые формируют основы экономики знаний. В работе анализируются проблемы и пути формирования рынка программного обеспечения. Описивается сущность национальной модели рынка программных продуктов. Излагается структура индийской модели контрактного программирования. Исследуются основы израильско-скандинавской модели экспорта готовых продуктов и решений. Даются некоторые рекомендации по развитию рынка программных продуктов и инженерий.
\end{abstract}

Ключевые слова - экономика знаний, рынок программного обеспечения, контрактное программирование, экспорт программных продуктов и решений

\section{I. ВВЕДЕНИЕ}

Одним из важных направлений развития общества в развитых странах является ее всесторонняя информатизация. Она составляет основную часть интеграционных процессов и глобализации в мире. Внедрение и использование новейших достижений в области информационно-коммуникационных технологий (ИКТ), привлечение крупнейших мировых производителей компьютерного и коммуникационного оборудования являются одними из необходимых условий перехода к новому этапу развития экономики [1].

В мировом сообществе считается, что обеспечение беспрерывного экономического роста каждой развитой и развивающейся страны требует развития науки, инновации, техники, ИКТ, потому что от них зависит определение направлений развития экономики, формирование человеческого капитала, эффективное использование интеллектуального потенциала, повышение жизненного уровня населения. Человеческий капитал составляет основную часть национального богатства развитых стран. Это считается проявлением развития науки и инновации, другими словами, экономики информации и знаний. В настоящее время во многих странах претворяется в жизнь целый ряд экономико-технических практических мероприятий. Создаются специальные экономические зоны и технопаркы, осуществляются стимулирующие программы малого инновационного бизнеса, предпринимаются шаги в области улучшения кредитно-финансовой обстановки создания малого и среднего бизнеса, выделяются нужные бюджетные средства на фундаментальную и прикладную науку и т.д. [2]. В этих условиях необходимо построение рынка программных продуктов и новой национальной инновационной инфраструктуры и системы, которые составляют основу будущего экономического развития страны. Поэтому в последние годы в области осуществления Национальной Стратегии по Информационному обществу Азербайджана [3] была обеспечена стремительная интеграция страны в общемировое электронное пространство, получены важные результаты в направлении создания электронного правительства, формирования экономики знаний, информационной безопасности и прочее. Исходя из этого, можно отметить, что анализ проблемы и исследование пути формирования и развития рынка программного обеспечения страны и разработка соответствующих рекомендаций в этом направлении считаются одними из актуальных задач. В этом аспекте является актуальным значение изучения опыта формирования и организации мирового рынка программных продуктов.

\section{II. ФОРМИРОВАНИЕ ЭКОНОМИКИ}

\section{ИНФОРМАЦИИ, ЗНАНИЙ, ИКТ И ИННОВАЦИЙ}

В настоящее время во многих странах мира формируется экономика знаний [4]. К этой экономике в основном относятся промышленные изобретения, инновации, товарные знаки и патенты, программные продукты, базы данных, продукты, медиа-биоэкономика, космическая информатика, информационные системы, инфраструктура, интеллектуальная собственность, высокие технологии и т.д., которые являются результатом деятельности различных отраслей и предприятий.

Для формирования экономики знаний очень важно создание новой экономической модели, обеспечивающей широкое распространение информации и знаний, а также дающей конкурентное превосходство на международном рынке. Общество знаний как составляющая информационного общества (ИО) формируется с помощью информационных технологий. В глобальном информационном обществе знание превращается в товар. А общество знаний в свою очередь формирует экономику знаний. Производимые в экономике знаний продукты являются высоконаукоемкими. Существует зависимость между информационной асимметричностью и экономическим неравенством. Наиболее значительным потенциалом развитых стран являются научные и 
образовательные центры этих стран, высокоинтеллектуальные люди [5].

В экономике знаний, в которой сосредоточились производство, присвоение, распространение, защита знаний, доминируют инновации, ИКТ. США, Япония, Южная Корея, Китай и ряд западноевропейских стран уже достигли такого уровня. В последнее время 60-80\% экономического роста названных стран приходится именно на знания (науку, образование, наукоемкие отрасли), инновации и ИКТ.

Безусловно, ведущее место в формировании знаний занимают информация и программные продукты. Здесь они выступают как база экономики знаний. Отличием экономики информации от экономикой знаний является то, что информация имеет сырьевой характер. Другими словами, в экономике знаний для производства новой продукции информация играет роль «сырья». Необходимость обработки полученного или производимого «сырья» создает потребность в специализированных кадрах ученых, специалистов, благоприятствует созданию хорошей среды для их успешной работы.

Согласно принятой Стратегической дорожной карте [6] за предстоящие годы планируется завершить процесс формирования национальной инновационной системы, обеспечивающей использование, освоение и распространение новых знаний и технологий в соответствии с требованиями информационного общества в Азербайджане. За это время станет возможно дальнейшее развитие инфраструктуры ИКТ, улучшение качества оказываемых населению электронных услуг, формирование рынка программных продуктов, обеспечение на территории страны широкополосного, дешевого и качественного выхода в интернет. Станут широко доступными дистанционное обучение, электронная торговля, теле-медицина и другие современные услуги.

Для того, чтобы заложить основу для перехода от традиционной экономики к экономике знаний, следует, в первую очередь, развивать человеческий капитал, что влечет за собой повышение роли программных продуктов, ИКТ, виртуального обучения, компьютерных сетевых знаний. К 2020 году в самых отдаленных сёлах Азербайджана завершится процесс обеспечения граждан всеми необходимыми для повседневной жизни коммуникационными средствами.

В результате выхода телекоммуникационных спутников страны на геостационарную орбиту будет обеспечена надежная спутниковая связь, что усилит информационную безопасность страны. Найдут свое широкое применение в телекоммуникационных сетях новые технологии. Будет организовано пакетное вещание национальных теле- и радиопрограмм со спутника. Одновременно также планируется запуск на орбиту низкоорбитальных спутников, что обеспечит эффективную защиту окружающей среды и деятельность в сфере национальной безопасности.
Для обеспечения выхода страны на региональный рынок ИКТ-услуг будут реализованы такие проекты, как создание информационной магистрали, региональных информационных ресурсов и систем сетевого управления. С целью формирования «Электронного правительства» в госструктурах намечается расширение сферы применения современных информационно-коммуникационных технологий, обеспечение безопасного обмена информацией между ними на основе единой инфраструктуры и предоставление населению электронных услуг. Намечается обеспечение интеграции государственных информационных ресурсов и систем на основе единых технологических стандартов, формирование единого информационного пространства. В центре внимания останутся вопросы предотвращения глобальных кибератак, поступающих в страну, защиты от всевозможных угроз информационных процессов, а также информационных ресурсов и систем государственных органов. Все эти мероприятия дадут дополнительный импульс для развития рынка соответствующих программных продуктов.

Исследования показывают, что сегмент рынка программного обеспечения (ПО) может стать весьма существенным в структуре экспорта страны [7]. В настояшее время в республике для формирования и развития рынка ПО можно выбрать одну из возможных моделей развития.

\section{III. СУШНОСТЬ И СТРУКТУРА НАЦИОНАЛЬНОЙ МОДЕЛИ ВНУТРЕННОГО РЫНКА ПО}

Суть национальной модели состоит в продаже товаров и услуг на внутреннем рынке. Структура модели включает компьютерную коммерцию, софтверный бизнес, ориентированный на азербайджанских клиентов и Интернет-компании в области новых медиа и электронной коммерции в доменной зоне .az. Можно предположить, что у азербайджанских компаний при этой модели есть несколько крупных преимуществ над международными конкурентами. Первое и самое главное - знание местной специфики.

Следующее преимущество - большая и быстро развивающаяся община выходцев из Азербайджана во всем мире. Дело в том, что азербайджанцы за рубежом ассимилируются очень быстро. Их стойкое русско- и азербайджаноязычие, желание быть в курсе событий, происходящих в Азербайджане, достаточны, чтобы обеспечить интерес к стране. Это может обеспечить новому бизнесу "национальной модели" возможность разграничения рынка и за пределами Азербайджана.

Однако у национальной модели есть естественный предел. Трудно представить создание новых программных продуктов, на которые будет большой спрос. Поэтому в Азербайджане в будущем трудно будет поддерживать большое количество технологических компаний, работающих на внутренний рынок. Значит в процессе развития национальной модели необходимо учесть указанные проблемы. 


\section{IV. ИНДИЙСКАЯ МОДЕЛЬ КОНТРАКТНОГО ПРОГРАММИРОВАНИЯ}

Индийская модель представляет собой формирование и развитие в стране контрактного программирования $[8,9]$. Бизнес оффшорного программирования опирается на потребность в большом количестве нерегулярных, разовых или специальных программных работ, в особенности не требующих ничего, кроме большего количества кропотливой работы и нехватки инженеров в развитых странах. Именно на этой модели строят свой бизнес оффшорные программисты в Индии, на Тайване, в Сингапуре, Малайзии, Ирландии и Бразилии. Основными областями, где на их труд сейчас большой спрос, являются IT-услуги по реконструкции устаревших систем и созданию новых, их техническая поддержка, веб-дизайн и программные продукты, в том числе для электронного бизнеса. Создание бизнеса по “индийской модели" не особенно сложно. Однако, нельзя забывать, что в нынешных условиях Азербайджана также существуют определенные кадровые, технические, организационные проблемы, связанные с реализацией этой модели.

\section{V. МОДЕЛЬ ЭКСПОРТА ГОТОВЫХ ПРОДУКТОВ И РЕШЕНИЙ}

Третья израильско-скандинавская модель представляет собой экспорт готовых продуктов и решений на внешний международный рынок $[10,11]$. Этой моделью пользуются Израиль, Финляндия, Швеция, Исландия, Норвегия, Шотландия и т.д. Ежегодный объем экспорта IT-продукции в Израиле составляет более 15 млрд. долларов. В Индии этот показатель составляет около 5 млрд. долларов. В настоящее время израильская IT-индустрия включает более 3 тыс. IT-компаний. Стремительный рост рынка привел к тому, что Израиль испытывает нехватку программистов и стал прибегать к услугам оффшорных компаний. Израильская модель, дает определенные возможности для лидерства, которых нет ни у какой другой модели. Эта модель позволяет применить весь национальный интеллектуальный потенциал наиболее эффективным способом.

\section{VI. ОБЩЕЕ СОСТОЯНИЕ РЫНКА ПРОГРАММНОГО ОБЕСПЕЧЕНИЯ В АЗЕРБАЙДЖАНЕ}

Известно, что рынок программного обеспечения Азербайджана находится на начальном этапе формирования. Однако, проведенные техникоэкономические анализы показывают, что уровень многих программистов достаточно высок. Поэтому ITобразованию Азербайджана необходима государственная поддержка, что позволит стране сделать качественный скачок в этой сфере.

По данным Международного торгового центра (ITC) примерно в 300 миллионов долларов оценивается среднесрочный экспортный потенциал Азербайджана в сфере информационно-коммуникационных технологий $[12,13]$. Согласно данным ITC, в IT-сфере Азербайджан имеет наибольший экспортный потенциал в подготовке программного обеспечения, так как компании в этом сегменте могут развиваться очень быстрыми темпами.

Следует отметить, что по некоторым оценкам, до $80 \%$ используемого в Азербайджане программного обеспечения (ПО) не является лицензионным. Использование и распространение пиратского софта с одной стороны развивает рынок программного обеспечения в республике, а с другой стороны мешает формированию национальных программистов, способных создавать конкурентноспособное ПО. По предварительным исследованиям ITC, в Азербайджане занято более 20 тысяч программистов. Согласно мировым стандартам, один программист в среднем может производить софтверной продукции на 50 тысяч долларов, тогда как сегодня в Азербайджане этот показатель намного ниже. Исходя из этого, в будущем ожидаемый объем произведенного программного обеспечения может составить в Азербайджане примерно 1 миллиард долларов.

\section{ЗАКЛЮЧЕНИЕ}

Подводя итоги сказанному выше, можно сформулировать требования, необходимые для быстро и уверенного развития отрасли ПО в Азербайджане. К ним относятся:

- рост качества услуг разработки ПО;

- реализация согласованной системы мер законодательного характера, направленной на создание благоприятных условий для развития индустрии информационных технологий в стране и привлечения в нее инвестиций;

- закрепление стратегического сотрудничества с важнейшими каналами сбыта, ведущими зарубежными ассоциациями и крупными объединениями бизнеса;

- активная работа профессиональных бизнесассоциаций;

- увеличение числа сертифицированных компаний в Азербайджане.

\section{ЛИТЕРАТУРА}

[1] А.Г.Алиев. Проблемы информатизации общества и экономики. Баку, “ЭЛМ”, 2003. Səh.460.

[2] Концепция развития «Азербайджан - 2020: взгляд в будущее». Баку, 29 декабря, r.2012, www.president.az

[3] Национальная стратегия по развитию информационного общества в Азербайджанской Республике на 2014-2020 годы 17.04.2014. www.mincom.gov

[4] С.П.Земцов, В.М.Комаров. Формирование экономики знаний в регионах России, Инновации. № 10 (204), 2015. стр. 29-38

[5] S. Allen Warren . Participation and Knowledge Exchange in a HybridEconomic Software Community. Journal of the Knowledge Economy, 2016, pp 1-15

[6] А.Г.Алиев. Теоретико-прикладные аспекты информатизации гуманитарных отраслей. Баку, “ЭЛМ”, 2006, 474 стр.

[7] Milli iqtisadiyyat və iqtisadiyyatın əsas sektorları üzrə strateji yol xəritələri. Bakı, 6 dekabr 2016-c1 il. www.president.az 
[8] К.И.Аблаева, Э.А.Умеров. Характерные особенности программного продукта на рынке товаров и услуг Информационно-компьютерные технологии в экономике, образовании и социальной сфере. 2016, № 3 (13). С. 179-186

[9] И.С.Ашманская. Развитие сектора информационных технологий в Индии: роль государства. Вестник МГИМО Университета. 2014, № 6 (39), стр.126-132

[10] Г.А.Ботвин, А.А.Салтан. Моделирование современного рынка программного обеспечения. Экономика и управление. 2014. № 2 (100). C. $51-58$

[11] Ю.П.Ехлаков, А.А.Ефимов. Функциональные модели бизнеспроцессов фирмы посредника на рынке программных продуктов. Бизнес-информатика. 2010. № 1 (11). С. $22-29$

[12] Ф.Казымов. Рынок ПО Азербайджана, Internet, №80, Баку, 2002.

[13] http://www.intracen.org 